\title{
Gain and subsequent loss of lung function after lung volume reduction surgery in cases of severe emphysema with different morphologic patterns
}

\author{
Konrad E. Bloch, MD \\ Carmina L. Georgescu, MD \\ Erich W. Russi, MD \\ Walter Weder, $M D^{\mathrm{b}}$
} From the Pulmonary a and Thoracic Sur-
gery $^{\mathrm{b}}$ Divisions, University Hospital of $\mathrm{Zu}-$ rich, Switzerland.

Supported by Grant No. 3200-043358;95.1 from the Swiss National Science Foundation, and by the Zurich Lung League.

Read at the Eighty-first Annual Meeting of The American Association for Thoracic Surgery, San Diego, Calif, May 6-9, 2001.

Received for publication May 5, 2001; revisions requested July 11, 2001; revisions received Aug 6, 2001; accepted for publication Aug 15, 2001.

Address for reprints: Walter Weder, MD, Division of Thoracic Surgery, University Hospital of Zürich, Rämistrasse 100, CH-8091 Zurich, Switzerland (E-mail: walter.weder@chi.usz.ch).

J Thorac Cardiovasc Surg 2002;123:845-54 Copyright $\odot 2002$ by The American Association for Thoracic Surgery

$0022-5223 / 2002 \$ 35.00+0 \quad \mathbf{1 2 / 6 / 1 2 0 7 3 1}$ doi: $10.1067 / \mathrm{mtc} .2002 .120731$
Objective: Surgical lung volume reduction improves lung function and dyspnea in advanced emphysema to a variable degree. Because long-term results with this procedure are scant, we prospectively investigated lung function over several years after lung volume reduction surgery with regard to emphysema morphology.

Methods: Bilateral video-assisted thoracoscopic lung volume reduction surgery was performed in severely symptomatic patients with marked hyperinflation caused by advanced nonbullous emphysema. Emphysema heterogeneity was visually graded on chest computed tomography. Symptoms and lung function were assessed before the operation and 3,6, and then every 6 months after the operation.

Results: A total of 115 patients with a median forced expiratory volume in 1 second of $0.73 \mathrm{~L}$ ( $27 \%$ of predicted value) underwent lung volume reduction surgery. Follow-up extended over a median of 37 months. Median forced expiratory volume in 1 second significantly increased within 6 months after the operation by $37 \%$ in homogeneous $(n=27)$, by $38 \%$ in intermediately heterogeneous $(n=37)$, and by $63 \%$ in markedly heterogeneous emphysema $(\mathrm{n}=51, P<.05$ vs other morphologies). Maximal forced expiratory volume in 1 second was reached within 6 months after lung volume reduction surgery and decreased in the first postoperative year by $0.16 \mathrm{~L}$ per year in homogeneous, by $0.19 \mathrm{~L}$ per year in intermediately heterogenous, and by $0.32 \mathrm{~L}$ per year in markedly heterogeneous emphysema $(P<.01$ vs other morphologies). The decline in forced expiratory volume in 1 second over subsequent years decelerated according to an exponential decay and was similar for all morphologic types (median annual decrease of $0.09 \mathrm{~L} \mathrm{[9 \% ]).}$

Conclusions: Lung volume reduction surgery improves lung function in severe homogeneous and, to an even greater extent, heterogeneous emphysema. Forced expiratory volume in 1 second peaks within 6 months postoperatively. The subsequent decline is most rapid in the first year and slows down in succeeding years according to an exponential decay. Therefore, long-term functional results of lung volume reduction surgery may be more favorable than expected from linear extrapolations of short-term observations. 


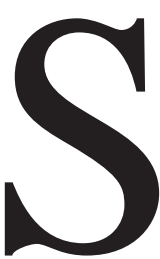

everal prospective case series ${ }^{1-5}$ and, more recently, a few prospective, randomized, controlled trials ${ }^{6-8}$ have demonstrated a relief of dyspnea and an improvement in lung function, exercise tolerance, and quality of life after lung volume reduction surgery (LVRS) for emphysema. The amount of improvement is variable and may depend on various factors, including cause and morphologic types of emphysema, preoperative lung function, and amount of resected emphysematous lung tissue.

Certain authors have stressed that patients with distinct regional differences in tissue destruction (ie, with markedly heterogeneous emphysema) on computed tomographic (CT) scanning, perfusion scintigraphy, or both profit most from LVRS because nonfunctional areas identified by means of imaging techniques are the ideal targets for resection. ${ }^{9,10}$ In previous analyses we corroborated this concept, but more important, we were able to demonstrate that even patients with a uniform pattern of emphysematous destruction (ie, a homogenous type) had significant and clinically relevant improvement after the operation. ${ }^{11,12}$ Because data on longterm outcome after LVRS are scant and have not been analyzed with regard to the potential effects of emphysema morphology, we prospectively investigated the initial gain and the subsequent loss of lung function over several years after LVRS in patients with various degrees of emphysema heterogeneity.

\section{Methods}

\section{Patients}

The patients participated in a prospective trial on the outcome of LVRS. ${ }^{2}$ As described previously, ${ }^{13}$ patients with nonbullous pulmonary emphysema were included when they were severely symptomatic despite optimal medical therapy, had severe airflow obstruction (forced expiratory volume in 1 second $\left[\mathrm{FEV}_{1}\right]$ of $<40 \%$ of predicted value), and had pulmonary hyperinflation (residual volume [RV] of $>200 \%$ of predicted value, RV/total lung capacity of $>0.60)$. Severely impaired carbon dioxide diffusing capacity $(<20 \%$ of predicted value) and significant coronary artery disease represented the major exclusion criteria for the current study. No systematic rehabilitation was performed at our center before or after the operation, but the majority of patients had undergone rehabilitation at other institutions before referral. The study was approved by the hospital ethics committee, and informed consent was obtained from the patients.

\section{Surgical Intervention}

LVRS was performed by means of bilateral, video-assisted, stapled (buttressed or nonbuttressed with bovine pericardium according to the protocol of a previous study ${ }^{14}$ ) resection of approximately $30 \%$ of lung volume. ${ }^{1}$ Target areas were identified, by means of analysis of the CT scans and perfusion scintiscans, as the lung zones with the most pronounced emphysematous alteration and the greatest reduction in perfusion. In addition, target areas were selected on the basis of visual observation of areas with delayed resorption atelectasis during the surgical intervention. ${ }^{12}$ Patients were operated on in the supine position if resection in the upper lobes was planned. For lower lobe resections, patients were placed in a lateral decubitus position and turned to the other side after completion of the first side.

\section{Measurements}

Clinical evaluation. Spirometry, whole-body plethysmography, and measurement of carbon monoxide diffusing capacity were performed (6200 Autobox; SensorMedics, Yorba Linda, Calif) according to standard criteria after inhalation of 2 puffs of albuterol. Arterial blood for blood gas analysis was obtained while the patient was sitting and breathing room air. Cotinine concentration of the urine was determined as a marker for smoking. ${ }^{15}$ For the purpose of the current analysis, a patient was considered a smoker if his or her urinary cotinine concentration was greater than $1000 \mathrm{mg} / \mathrm{L}$, if greater than $5 \%$ of his or her hemoglobin was saturated with carbon monoxide, or if he or she reported regular cigarette smoking.

For assessment of the 6-minute walking distance, the patients walked along the same hospital hallway without supplemental oxygen. Severity of dyspnea was graded by the American Thoracic Society modified Medical Research Council (MRC) dyspnea score, with a scale ranging from 1 to $4 .{ }^{16}$ Baseline and follow-up examinations were performed within 1 month before LVRS, at 3 and 6 months after LVRS, and every 6 months thereafter.

Imaging techniques. Preoperative chest $\mathrm{CT}$ examinations were performed on a Somatom plus 4 scanner (Siemens, Erlangen, Germany) with a high-resolution technique by using an increment of $15 \mathrm{~mm}$ and a slice thickness of 1 $\mathrm{mm}$ at $140 \mathrm{kV}$ and $11 \mathrm{~mA}$. Heterogeneity of emphysema distribution was graded according to our semiquantitative staging system, which comprises 3 degrees ${ }^{11}$ :

1. Markedly heterogeneous: a distinct regional difference in severity of emphysema is present in at least 2 adjacent lung segments of either lung

2. Intermediately heterogeneous: a distinct regional difference in severity of emphysema may be present maximally in the area of one or more than one but not in adjacent segments of either lung

3. Homogeneous: no regional or only very minor differences in severity of emphysema are appreciable

Lung perfusion scans were also obtained as a help for identification of target areas in cases with homogeneous emphysema distribution on CT scans. ${ }^{12}$

\section{Data Analysis and Statistics}

Summary statistics are presented as medians and quartile ranges because certain variables were not normally distributed. ${ }^{17}$ To perform statistical comparisons, data were logarithmically transformed to obtain a normal distribution, as confirmed with the Kolmogorov-Smirnov statistic. ${ }^{18}$ Changes in variables over time within and among the 3 groups of patients with different emphysema heterogeneity were evaluated by analysis of variance, followed by Newman-Keuls multiple comparisons where appropriate. Correlation of baseline variables with changes in $\mathrm{FEV}_{1}$ after LVRS were performed by means of multiple linear regression analyses. 


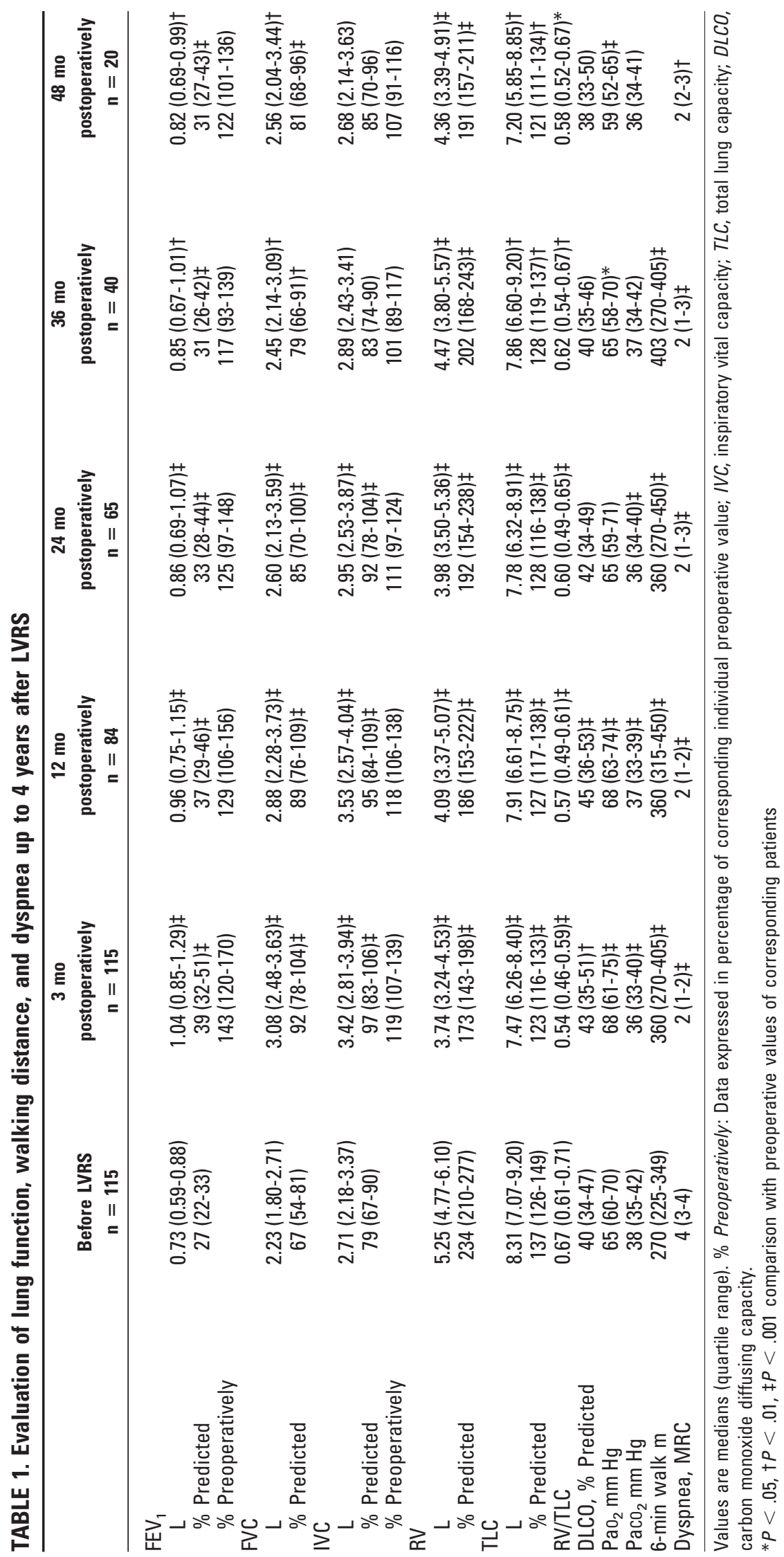


TABLE 2. Effect of LVRS on lung function in patients with different emphysema morphology

\begin{tabular}{|c|c|c|c|c|c|}
\hline & Before LVRS & $\begin{array}{c}3 \text { months } \\
\text { postoperatively }\end{array}$ & $\begin{array}{c}12 \text { months } \\
\text { postoperatively }\end{array}$ & $\begin{array}{c}24 \text { months } \\
\text { postoperatively }\end{array}$ & $\begin{array}{c}48 \text { months } \\
\text { postoperatively }\end{array}$ \\
\hline \multicolumn{6}{|c|}{ Markedly heterogeneous emphysema } \\
\hline $\mathrm{n}$ & 51 & 51 & 41 & 35 & 8 \\
\hline \multicolumn{6}{|l|}{$\mathrm{FEV}_{1}$} \\
\hline $\mathrm{L}$ & $0.81(0.64-0.96) \S$ & $1.20(0.97-1.50) \ddagger$ & $1.11(0.82-1.40) \ddagger$ & $0.96(0.80-1.25) \ddagger$ & $1.11(0.78-1.40)^{*}$ \\
\hline$\%$ Predicted & $27(21-33)$ & $42(36-54) \ddagger$ & $39(29-48) \ddagger$ & $35(29-45) \ddagger$ & $37(28-46)^{*}$ \\
\hline \multicolumn{6}{|l|}{ IVC } \\
\hline $\mathrm{L}$ & $2.87(2.24-3.54)$ & $3.73(3.16-4.37) \ddagger$ & $3.85(3.13-4.34) \ddagger$ & $3.37(2.86-4.20)^{*}$ & $3.63(2.59-5.36)$ \\
\hline$\%$ Predicted & $79(67-90)$ & $98(86-111) \ddagger$ & $105(87-118) \ddagger$ & $96(81-110) \dagger$ & $85(62-114)$ \\
\hline RV/TLC & $0.66(0.59-0.71)$ & $0.51(0.42-0.56) \ddagger$ & $0.52(0.44-0.59) \ddagger$ & $0.54(0.43-0.62) \ddagger$ & $0.53(0.45-0.63) \dagger$ \\
\hline \multicolumn{6}{|c|}{ Intermediately heterogeneous emphysema } \\
\hline n & 37 & 37 & 23 & 14 & 7 \\
\hline \multicolumn{6}{|l|}{$\mathrm{FEV}_{1}$} \\
\hline L & $0.69(0.56-0.85)$ & $0.97(0.79-1.15) \ddagger$ & $0.94(0.66-1.05) \ddagger$ & $0.71(0.61-1.06)$ & $0.74(0.52-0.87)$ \\
\hline$\%$ Predicted & $26(24-32)$ & $37(31-45) \ddagger$ & $32(27-45) \ddagger$ & $32(25-47)^{*}$ & $31(25-37)$ \\
\hline \multicolumn{6}{|l|}{ IVC } \\
\hline $\mathrm{L}$ & $2.53(2.02-3.41)$ & $3.03(2.54-3.97) \ddagger$ & $3.35(2.46-4.01) \dagger$ & $2.73(2.36-3.55)$ & $2.53(1.72-2.81)$ \\
\hline$\%$ Predicted & $80(65-86)$ & $97(82-105) \ddagger$ & $95(82-107) \ddagger$ & $89(78-97)$ & $85(71-95)$ \\
\hline RV/TLC & $0.67(0.61-0.72)$ & $0.55(0.51-0.60) \ddagger$ & $0.57(0.50-0.61) \ddagger$ & $0.61(0.50-0.65)$ & $0.61(0.56-0.71)$ \\
\hline \multicolumn{6}{|c|}{ Homogeneous emphysema } \\
\hline $\begin{array}{l}\mathrm{n} \\
\mathrm{FEV}\end{array}$ & 27 & 27 & 20 & 16 & 5 \\
\hline $\mathrm{L}_{1}$ & $0.67(0.55-0.75)$ & $0.89(0.76-1.07) \ddagger$ & $0.87(0.70-0.97) \ddagger$ & $0.79(0.58-0.94) \dagger$ & $0.83(0.68-0.87)$ \\
\hline$\%$ Predicted & $25(23-32)$ & $36(29-46) \ddagger$ & $35(29-40) \ddagger$ & $31(28-40) \dagger$ & $29(27-32)$ \\
\hline \multicolumn{6}{|l|}{ IVC } \\
\hline $\mathrm{L}$ & $2.51(2.10-3.24)$ & $3.07(2.50-3.58) \ddagger$ & $2.57(2.38-3.76)^{*}$ & $2.58(2.11-3.14)^{*}$ & $2.85(2.27-3.24)$ \\
\hline$\%$ Predicted & $79(68-91)$ & $92(82-102) \ddagger$ & $91(80-104)^{*}$ & $84(76-98)$ & $86(71-96)$ \\
\hline $\mathrm{RV} / \mathrm{TLC}$ & $0.68(0.64-0.71)$ & $0.56(0.52-0.59) \ddagger$ & $0.59(0.56-0.62) \dagger$ & $0.62(0.61-0.67)$ & $0.60(0.57-0.60)$ \\
\hline
\end{tabular}

Values are medians (quartile range). IVC, Inspiratory vital capacity; $T L C$, total lung capacity.

${ }^{*} P<.05 ; \dagger P<.01 ; \ddagger P<.001$ for comparison to respective preoperatively value; $\S P<.05$ for comparisons of preoperative values vs. intermediately heterogeneous and homogeneous, see Table 3 for comparisons among heterogeneity groups at subsequent time points.

In each patient, elapsed time after the operation when the individual maximal value of $\mathrm{FEV}_{1}\left(\mathrm{FEV}_{1} \mathrm{max}\right)$ was reached was noted, along with the corresponding gain in $\mathrm{FEV}_{1}$. The maximal gain was defined as the difference between the maximal minus the preoperative value of $\mathrm{FEV}_{1}$ and expressed in liters and in percentages of the preoperative value. Graphic display of the individual time course of $\mathrm{FEV}_{1}$ after $\mathrm{FEV}_{1}$ max suggested an exponential decay. The decrease in $\mathrm{FEV}_{1}$ in the first year after the operation and the median yearly decrease over subsequent years were determined to capture this phenomenon numerically. Elapsed time from the operation to the time when $\mathrm{FEV}_{1}$ had fallen below $\mathrm{FEV}_{1}$ max minus half the maximal gain was also computed. Furthermore, the decline of $\mathrm{FEV}_{1}$ was modeled by fitting an exponential equation to the data of each individual patient according to the following equation:

$$
\mathrm{FEV}_{1}(\mathrm{t})=\mathrm{FEV}_{1} \mathrm{max} \cdot \mathrm{e}^{-\mathrm{t} / \tau},
$$

where $\mathrm{t}$ corresponds to the time elapsed since $\mathrm{FEV}_{1} \max$ and $\tau$ to the time constant of the exponential decay. The half-life of $\mathrm{FEV}_{1}$ expresses the time when $\mathrm{FEV}_{1}$ reaches the value of 0.5 times $\mathrm{FEV}_{1}$ max. It is calculated as follows:

$$
\text { Half-life }=\ln (0.5 / \tau) \text {. }
$$

Data from individual patients were included only if more than 4 observations were available and if the regression of predicted versus observed data was statistically significant.

\section{Results}

\section{Preoperative Findings}

Data of a total of 115 consecutive patients (43 female patients) were available for analysis. Median patient age at the time of the operation was 65 years (range, 38-78 years). Baseline characteristics and follow-up data are summarized in Table 1. According to the inclusion criteria for the operation, the patients had severe dyspnea and pronounced airflow obstruction and hyperinflation preoperatively. In 14 patients $\mathrm{PaO}_{2}$ was less than $55 \mathrm{~mm} \mathrm{Hg}$, and in 15 patients $\mathrm{PaCO}_{2}$ was greater than $45 \mathrm{~mm} \mathrm{Hg}$ (maximal value, $51 \mathrm{~mm}$ $\mathrm{Hg}$ ). Six-minute walking distance was limited to 35 to $450 \mathrm{~m}$. Eleven patients had $\alpha_{1}$-antitrypsin (Pi ZZ) deficiency. Chest CT scoring revealed markedly heterogeneous emphysema distribution in 51, intermediately heterogeneous emphysema distribution in 37, and homogeneous emphysema distribution in 27 patients. Preoperative $\mathrm{FEV}_{1}$ was greater in the group with markedly heterogeneous em- 
physema distribution (median $\mathrm{FEV}_{1}, 0.81 \mathrm{~L}$ ) than in the other 2 groups (Table 2). However, the medians in $\mathrm{FEV}_{1}$ expressed as a percentage of predicted values (range, 25\%$27 \%$ ) were not statistically different among groups.

\section{Postoperative Course in the Entire Cohort}

Perioperative mortality (within 30 days of the operation) was $2(<2 \%)$ of 115 . Postoperative observation extended up to 78 months (median, 37 months; quartile range, 20-54 months). The loss to follow-up was 5, 9, 12, and 14 patients at 1, 2, 3, and 4 years after LVRS. In 5 of these patients, lung transplantation had been performed. The cumulative numbers of deaths at 1,2,3, and 4 years after the operation were $6,16,24$, and 28, respectively. Maximal $\mathrm{FEV}_{1}$ after the operation was achieved within 3 to 6 months. At that time, the relative decrease in RV $(1-\mathrm{RV}$ after LVRS/RV before LVRS, an estimate of the reduction of lung volume in situ ${ }^{19}$ ) was $29 \%$ (quartile range, 19\%-39\%).

In Table 1 the course of lung function, walking distance, and dyspnea is summarized for all patients and grouped according to the length of postoperative observation. In the first year after the operation, $\mathrm{FEV}_{1}$ measured in absolute volume units fell by a median of $0.24 \mathrm{~L}$ per year (quartile range, 0.11-0.43). The median decrease in $\mathrm{FEV}_{1}$ expressed as a percentage of the individual maximal value was $22 \%$ per year (quartile range, $12 \%-36 \%$ ) in the first postoperative year. Over subsequent years, the median annual decline was significantly reduced to $0.09 \mathrm{~L}$ per year (quartile range, $0.05-0.15 \mathrm{~L}$ per year; $\mathrm{n}=80 ; P<.00001$ ), corresponding to a yearly relative loss of $\mathrm{FEV}_{1}$ of $9 \%$ per year (quartile range, $4 \%-16 \%$ per year; $\mathrm{n}=80 ; P<.0005$ vs first year values). After a median duration of 12 months after the operation (quartile range, 9-24 months; $\mathrm{n}=100$ patients), half of the gain of $\mathrm{FEV}_{1}$ was lost (ie, $\mathrm{FEV}_{1}$ had fallen from $\mathrm{FEV}_{1}$ max to below the value of $\mathrm{FEV}_{1}$ max minus half the maximal gain).

In 60 patients in whom an exponential function could be fitted to the decay in $\mathrm{FEV}_{1}$, there was a close match of predicted value with observed data (median coefficients of determination $r^{2}=0.88$; quartile range, 0.82-0.95; $P<$ $.05)$. Figure 1 shows the changes in $\mathrm{FEV}_{1}$ over the individual times of follow-up. The estimated time for $\mathrm{FEV}_{1}$ to fall back to the preoperative value was 38 months (quartile range, 21-64 months; Figures 1 and 2). The half-life of $\mathrm{FEV}_{1}$ (ie, the time required for $\mathrm{FEV}_{1}$ to fall to $50 \%$ of its initial maximal value) was estimated at 63 months (quartile range, 45-87; Figure 2). Neither resumption of smoking after the operation (documented in 14 patients at any time during their follow-up) nor $\alpha_{1}$-antitrypsin deficiency (present in 11 patients) had a statistically significant effect on the decline in $\mathrm{FEV}_{1}$ after the operation, as assessed by the measures mentioned above.

\section{Postoperative Course According to CT Morphology}

In Table 2 data are presented according to $\mathrm{CT}$ morphologic emphysema heterogeneity. The loss of follow-up was not statistically different among the 3 groups. The relative decrease in RV (1 - RV after LVRS/RV before LVRS) was $32 \%$ (quartile range, $23 \%-42 \%$ ) in the group with markedly heterogeneous emphysema, 28\% (quartile range, 19\%-39\%) in the group with intermediately heterogeneous emphysema, and $22 \%$ (quartile range, $19 \%-31 \% ; P<.5$ vs markedly heterogeneous) in the group with homogeneous emphysema. The functional gain was greatest in the group with markedly heterogeneous emphysema, but in patients with intermediately heterogeneous and homogeneous emphysema, significant functional and symptomatic improvements were also achieved (Table 2).

Figure 1 provides a graphic display of the initial gain and subsequent loss of $\mathrm{FEV}_{1}$ in the 3 groups of patients with different emphysema morphologic patterns. The absolute and relative gain in $\mathrm{FEV}_{1}$ (in liters and in percentage of preoperative value, respectively) was greatest in markedly heterogeneous emphysema. There was a trend for a greater subsequent loss of $\mathrm{FEV}_{1}$ (in absolute volume units [ie, liters]) in markedly heterogeneous emphysema during the first and subsequent years compared with intermediately heterogeneous or homogeneous emphysema. However, neither the time until $50 \%$ of the individual gain was lost nor the relative decline (in percentage) over the first and subsequent years nor the half-life of $\mathrm{FEV}_{1}$ differed among groups of patients with different emphysema morphologic patterns (Table 3, Figures 1 and 2).

The baseline values and follow-up values at 3, 12, 24, 36, and 48 months after LVRS for diffusing capacity, blood gases $\left(\mathrm{PaO}_{2}\right.$ and $\left.\mathrm{PaCO}_{2}\right)$, 6-minute walking distance, and MRC dyspnea scores did not statistically differ among the 3 groups with different emphysema morphologic patterns, and the values are listed for the entire cohort in Table 1 . Data for the groups with different emphysema heterogeneity are therefore not shown.

\section{Discussion}

We prospectively studied mortality and functional and symptomatic improvement over several years after bilateral videothoracoscopic LVRS. The major improvement in airflow obstruction and hyperinflation achieved with LVRS was associated with significant relief of dyspnea and improved walking distance. The relatively long follow-up period (median, 37 months) allowed us to demonstrate for the first time that $\mathrm{FEV}_{1}$, after reaching its peak at 3 to 6 months after the operation, follows an exponential decay. Our analysis helps to better understand the evolution of lung function after LVRS by providing data on both the initial gain and the subsequent loss of $\mathrm{FEV}_{1}$ in emphysema of various degrees of heterogeneity (Figure 2). 

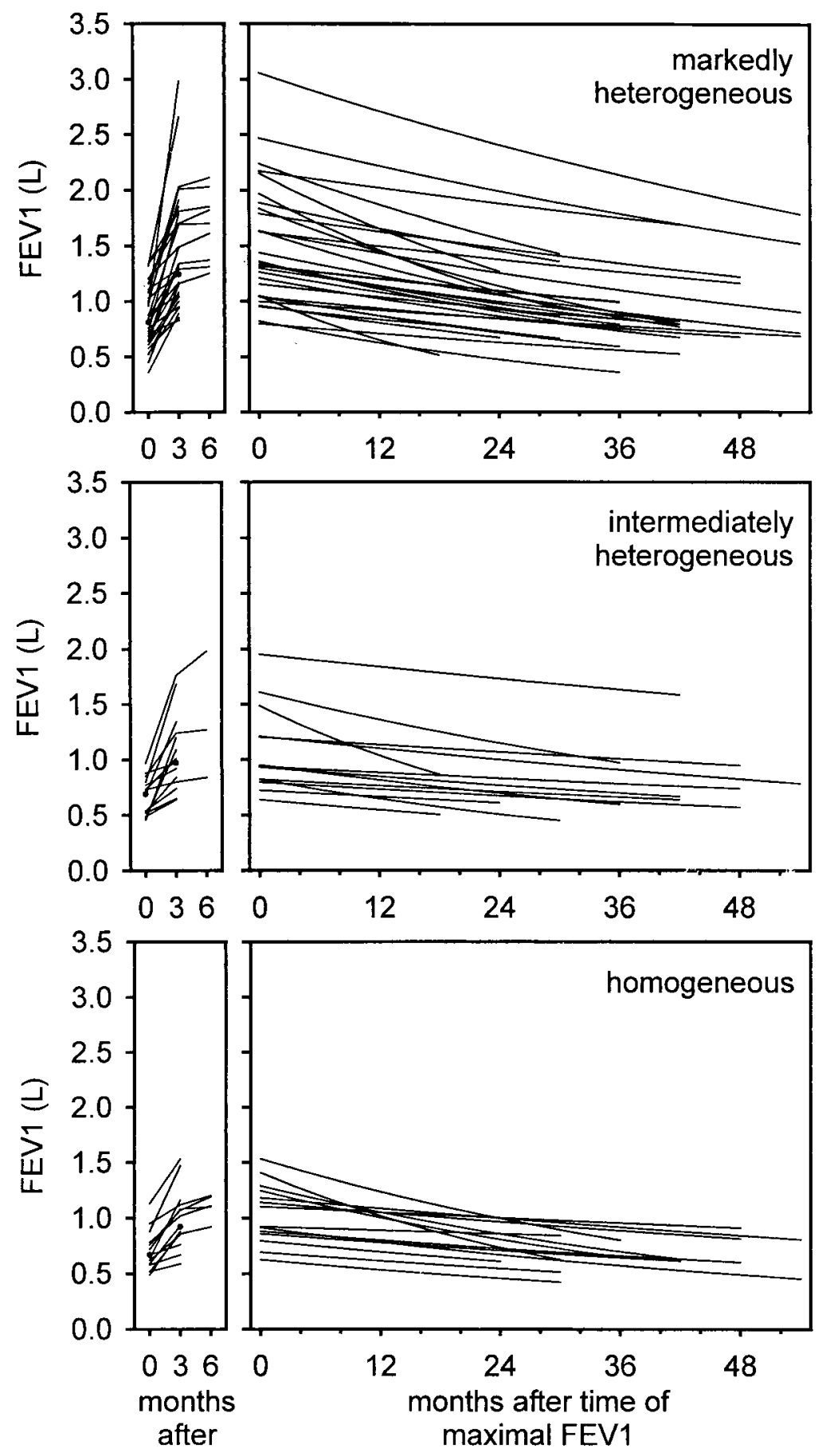

Figure 1. Left panels, The initial gain of individual $\mathrm{FEV}_{\mathbf{1}}$ in 60 patients is represented by lines connecting observed values before LVRS (plotted at time $\mathbf{0}$ months) with maximal values attained at $\mathbf{3}$ to $\mathbf{6}$ months after the operation. Right panels, The subsequent decline in $\mathrm{FEV}_{1}$ closely follows individually fitted exponential functions. These are represented by lines of a length corresponding to the individual elapsed time since $\mathrm{FEV}_{\mathbf{1}}$ started to decline from its maximal value (time $\mathbf{0}$ months after LVRS). Because of a certain degree of imprecision in the prediction equations, maximal measured $\mathrm{FEV}_{1}$ values (left panels) do not always coincide with the corresponding individual values at the beginning of the exponential decay (right panels). The upper, middle, and lower panels reflect the time course of $\mathrm{FEV}_{1}$ in patients with different emphysema morphologic patterns. 

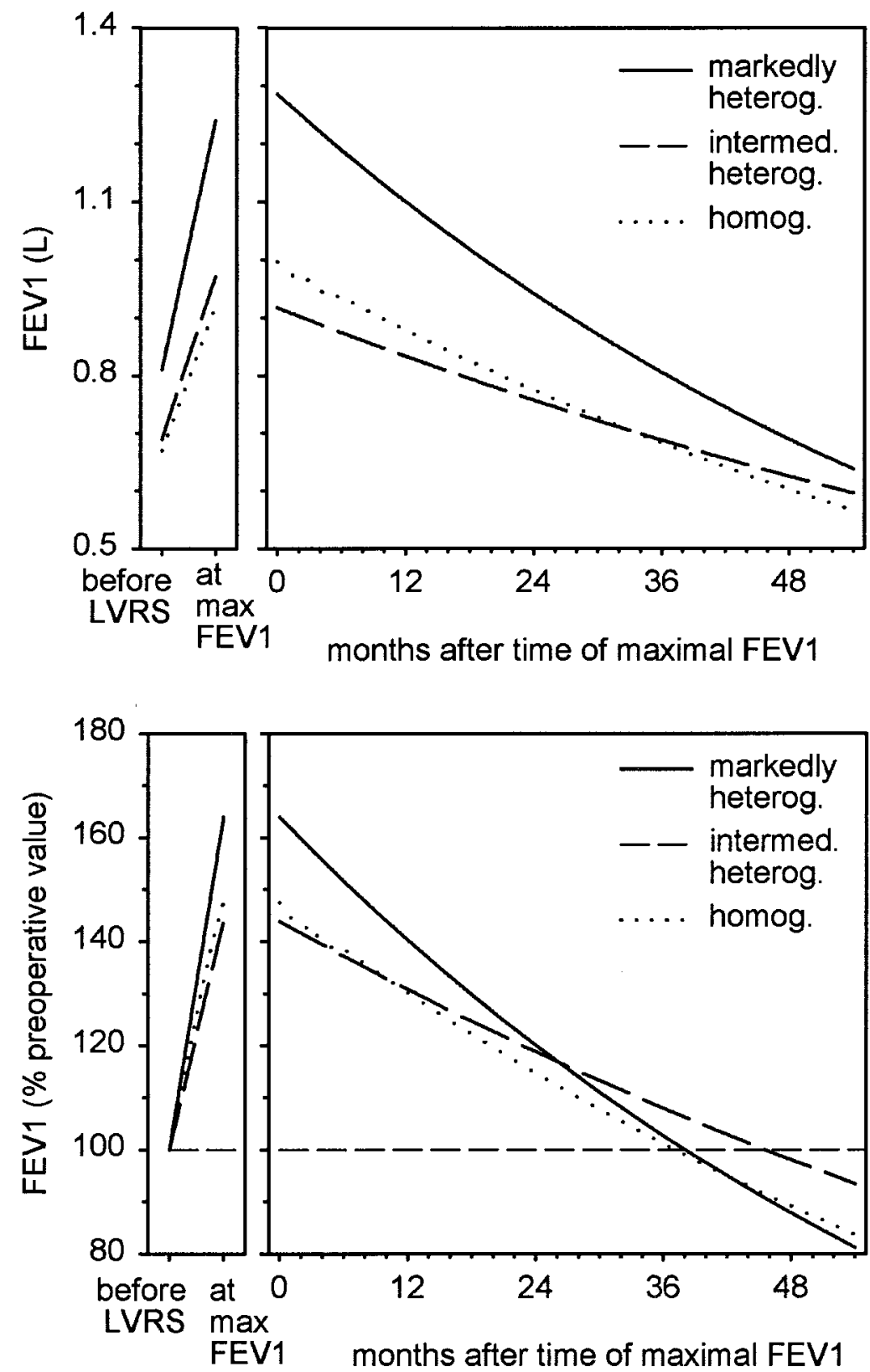

Figure 2. The layout of the figure is similar to that of Figure 1. On the left side, the panels represent the medians of measured gains in $\mathrm{FEV}_{1}$ for patients with markedly heterogeneous, intermediately heterogeneous, and homogeneous emphysema distribution. The right panels represent the exponential decay functions of $\mathrm{FEV}_{1}$ with origins and time constants corresponding to respective median values of the different heterogeneity groups. As explained

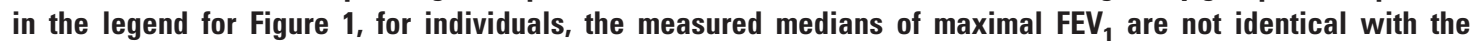
estimated beginning of the exponential decay. In the top panels $\mathrm{FEV}_{1}$ is expressed in absolute volume units (in liters). In the bottom panels $\mathrm{FEV}_{1}$ is expressed as a percentage of individual preoperative baseline values to provide an impression of relative changes over time. Although the absolute and relative gain in $\mathrm{FEV}_{\mathbf{1}}$ is greater in patients with markedly heterogeneous emphysema than in the other 2 groups, the subsequent decline expressed in relative volume units (in percentages) is similar for the 3 groups ( $P=$ not significant).

\section{Short-term Results After LVRS}

The short-term outcome achieved in the current study compares favorably with results achieved in other centers. With a value of less than $2 \%$, the perioperative mortality was at the lower end of the range of $0 \%{ }^{20}$ to $6 \%$ to $17 \%^{8}$ reported by others. Dyspnea decreased in all patients by at least 2 
TABLE 3. Changes in FEV 1 with LVRS according to emphysema morphology

\begin{tabular}{|c|c|c|c|c|c|c|}
\hline \multirow[b]{2}{*}{$\mathrm{FEV}_{\mathbf{1}}$} & \multicolumn{2}{|c|}{$\begin{array}{c}\text { Markedly } \\
\text { heterogeneous } \\
\text { emphysema }\end{array}$} & \multicolumn{2}{|c|}{$\begin{array}{c}\text { Intermediately } \\
\text { heterogeneous } \\
\text { emphysema }\end{array}$} & \multicolumn{2}{|c|}{$\begin{array}{l}\text { Homogeneous } \\
\text { emphysema }\end{array}$} \\
\hline & n & $\begin{array}{c}\text { Median } \\
\text { (quartile range) }\end{array}$ & n & $\begin{array}{c}\text { Median } \\
\text { (quartile range) }\end{array}$ & n & $\begin{array}{c}\text { Median } \\
\text { (quartile range) } \\
\end{array}$ \\
\hline \multicolumn{7}{|l|}{ Preoperative value } \\
\hline $\%$ predicted & 51 & $\begin{array}{l}0.81(0.64-0.96)^{*} \\
27(21-33)\end{array}$ & 37 & $\begin{array}{l}0.69(0.56-0.85) \\
26(24-32)\end{array}$ & 27 & $\begin{array}{l}0.67(0.55-0.75) \\
25(23-33)\end{array}$ \\
\hline Maximal value after LVRS & & & & & & \\
\hline $\begin{array}{l}\text { Maximal gain relative to } \\
\text { preoperative value }\end{array}$ & 51 & $1.24(1.04-1.61) \S$ & 37 & $0.97(0.79-1.19)$ & 27 & $0.92(0.78-1.13)$ \\
\hline L Baseline & 51 & $\begin{array}{l}0.48(0.27-0.68) \S \\
63(33-98)^{*}\end{array}$ & 37 & $\begin{array}{l}0.23(0.14-0.42) \\
38(20-62)\end{array}$ & 27 & $\begin{array}{l}0.26(0.18-0.39) \\
37(26-57)\end{array}$ \\
\hline $\begin{array}{l}\text { Measured time after LVRS until } \\
\text { gain was reduced to half of } \\
\text { initial maximal value, mo } \\
\text { Measured decrease from maximal } \\
\text { value during first year after LVRS }\end{array}$ & 46 & $18(12-24)$ & 31 & $12(6-24)$ & 23 & $18(12-30)$ \\
\hline $\begin{array}{l}\mathrm{L} \\
\%\end{array}$ & 43 & $\begin{array}{l}0.32(0.19-0.45) \ddagger \\
26(15-36)\end{array}$ & 25 & $\begin{array}{l}0.19(0.09-0.45) \\
22(12-37)\end{array}$ & 23 & $\begin{array}{l}0.16(0.08-0.35) \\
15(11-36)\end{array}$ \\
\hline $\begin{array}{l}\text { Measured yearly decrease in the } \\
\text { second and subsequent years } \\
\text { after LVRS }\end{array}$ & & & & & & \\
\hline $\begin{array}{l}\text { L/y } \\
\% / y\end{array}$ & 39 & $\begin{array}{l}0.12(0.07-0.17)^{*} \S \\
11(6-15) \S\end{array}$ & 22 & $\begin{array}{l}0.06 \S(0.02-0.11) \\
5 \S(2-11)\end{array}$ & 19 & $\begin{array}{l}0.08 \S(0.3-0.15) \\
8(2-18)\end{array}$ \\
\hline $\begin{array}{l}\text { Estimated half-life of exponential } \\
\text { decay, mo }\end{array}$ & & & & & & \\
\hline & 32 & $53(45-77)$ & 14 & $86(50-116)$ & 14 & 66 (41-99) \\
\hline
\end{tabular}

The number of cases $(n)$ for certain variables is less than that for preoperative values since certain patients were followed for less than 1 year after LVRS ( $n=24 / 115)$, because reduction of gain in $\mathrm{FEV}_{1}$ did not fall below half of initial value ( $\left.\mathrm{n}=15 / 115\right)$, or because exponential fit to observed postoperative $\mathrm{FEV}_{1}$ was not statistically significant ( $\mathrm{n}=9 / 13$ patients with 4 follow-up observations, $\mathrm{n}=11 / 67$ patients with $\geq 4$ follow-up observations).

${ }^{*} P<.05, \dagger P<.01$, and $\ddagger P=.05$ versus intermediately heterogeneous and homogeneous.

$\S P \leq .02$ for comparison of decrease versus first year within same group.

points on the MRC scale. In the entire cohort of 115 patients (Table 1), the significant reduction of lung volume, reflected by the $29 \%$ median decrease in $\mathrm{RV},{ }^{19}$ was associated with a median gain in $\mathrm{FEV}_{1}$ of $43 \%$. This is similar to the mean increase in $\mathrm{FEV}_{1}$ of $51 \%$ reported for 150 patients by Cooper and colleagues. ${ }^{3}$ In our 51 patients with markedly heterogeneous emphysema, $\mathrm{FEV}_{1}$ increased even more (ie, by $63 \%$; Table 3 ), which is close to the mean increase in $\mathrm{FEV}_{1}$ of $60 \%$ in 90 patients with heterogeneous emphysema treated with bilateral videothoracoscopic LVRS by Brenner and coworkers. ${ }^{4}$ In the 2 randomized studies for which the relative gain in $\mathrm{FEV}_{1}$ was reported, the corresponding values were less than $30 \%{ }^{20}$ and $53 \%,{ }^{7}$ respectively.

We were able to further substantiate our previous findings of a significant and clinically relevant functional and symptomatic benefit from LVRS in a larger number of patients with completely diffuse, homogenous emphysema followed over longer time periods than in the earlier reports. ${ }^{11,12}$ The significant differences in short-term outcome among groups of patients classified according to emphy- sema heterogeneity by means of visually scoring the chest CT illustrates the clinical relevance of our simple grading system ${ }^{11}$ and underlines an effect of morphologic factors on the success of LVRS. Nevertheless, the association of emphysema heterogeneity with favorable functional outcome is relatively modest and may, in part, be related to a greater extent of resection by the surgeon in heterogeneous emphysema, if target areas are clearly visualized on the CT.

\section{Evolution of Symptoms and Function Over Several Years}

Our data suggest that dyspnea is persistently relieved after LVRS in the majority of patients over at least 48 months (Table 1). Median walking distance also remained increased above preoperative levels over this time period. On the other hand, airflow obstruction and hyperinflation began to deteriorate after maximal improvement within 3 to 6 months after the operation. Within the first year after LVRS, the median loss of $\mathrm{FEV}_{1}$ in our entire cohort $(\mathrm{n}=91$ patients followed up over the first year) was $0.24 \mathrm{~L}$. This is consis- 
tent with a previous report ${ }^{4}$ of a mean decline in $\mathrm{FEV}_{1}$ of $0.255 \mathrm{~L}$ per year $(\mathrm{n}=90$ patients, mean follow-up of 420 days after the operation). Because this result ${ }^{4}$ reflects the slope of the linear regression of $\mathrm{FEV}_{1}$ versus time in patients with a mean follow-up that was close to 1 year, the resulting mean loss of $\mathrm{FEV}_{1}$ is comparable with the decrease in $\mathrm{FEV}_{1}$ documented in the first year in our cohort (Table 3).

Observation of changes in lung function over several years suggested a nonlinear course (Table 1). This was analyzed in greater detail for $\mathrm{FEV}_{1}$, which declined much more rapidly in the first than in subsequent years after LVRS (ie, group medians of the fall were between 0.16 and $0.32 \mathrm{~L}$ per year initially and between 0.06 and $0.12 \mathrm{~L}$ per year in the later course; $P<.0005$ vs fall in the first year; Table 3). This indicates that long-term trends in $\mathrm{FEV}_{1}$ after LVRS can not be derived by means of linear extrapolation of the early postoperative course. Instead, graphic representation and statistical analysis confirmed an exponential decay (Figures 1 and 2). In an individual patient $\mathrm{FEV}_{1}$ closely followed the course predicted by the following general equation:

$\mathrm{FEV}_{1}$ (at a given time [t] after the peak value)

$$
=\text { Maximal postoperative } \mathrm{FEV}_{1} \cdot \mathrm{e}^{-\mathrm{t} / \text { individual time constant }}
$$

A median of $88 \%$ in the variability of $\mathrm{FEV}_{1}$ could be explained accordingly, suggesting that the exponential function may provide a useful guide in the assessment and counseling of patients after LVRS. It is conceivable that our exponential model, which is different from the linear polynomial equation applied to describe the effects of smoking cessation and inhalation therapy on the course of $\mathrm{FEV}_{1},{ }^{21}$ performed well in capturing the much more striking effect of a surgical intervention such as LVRS.

Interestingly, the characteristics of exponential decay in $\mathrm{FEV}_{1}$, such as the observed time to half the initial gain in $\mathrm{FEV}_{1}$ (measured in 100 of 115 patients, Table 3 ) or the estimated half-life of $\mathrm{FEV}_{1}$ (computed for 60 patients) did not statistically differ among the 3 groups with different emphysema morphologic patterns (Figure 2). Because the exponential decay was fitted to data of patients with a follow-up of at least 21 months after the maximal postoperative $\mathrm{FEV}_{1}$ only (ie, postoperative observation $\geq 2$ years after LVRS) and because of mortality (16/115 patients at 2 years after LVRS) and losses to follow-up (9/115 patients at 2 years), the subgroup of 60 patients in whom this analysis could be performed may reflect a certain bias toward a more favorable course and, obviously, is representative for survivors over this time period only. Nevertheless, the prediction derived from 60 patients together with the time until half of the gain in $\mathrm{FEV}_{1}$ was lost (measured in 100 patients) may still be typical for the time course of the decay in $\mathrm{FEV}_{1}$ in many patients who undergo LVRS.

\section{Conclusions}

We confirmed that heterogeneity of emphysema distribution graded visually on the chest CT correlates with the degree of functional improvement in the first few months after LVRS. The early rate of decline in $\mathrm{FEV}_{1}$ from the maximal value in the first year after the operation was significantly greater than that in subsequent years, according to an exponential decay. Therefore, our data, obtained in a fairly large number of patients over several years, illustrate that the course of lung function in intermediate and long-term survivors of LVRS may be more favorable than previously expected from linear extrapolations of short-term observations.

\section{References}

1. Bingisser R, Zollinger A, Hauser M, Bloch KE, Russi EW, Weder W. Bilateral volume reduction surgery for diffuse pulmonary emphysema by video-assisted thoracoscopy. J Thorac Cardiovasc Surg. 1996;112: 875-82.

2. Hamacher J, Bloch KE, Stammberger U, Schmid RA, Laube I, Russi EW, et al. Two years' outcome of lung volume reduction surgery in different morphologic emphysema types. Ann Thorac Surg. 1999;68: 1792-8.

3. Cooper JD, Patterson GA, Sundaresan RS, Trulock EP, Yusen RD, Pohl MS, et al. Results of 150 consecutive bilateral lung volume reduction procedures in patients with severe emphysema. $J$ Thorac Cardiovasc Surg. 1996;112:1319-30.

4. Brenner M, McKenna RJJ, Gelb AF, Fischel RJ, Wilson AF. Rate of $\mathrm{FEV}_{1}$ change following lung volume reduction surgery. Chest. 1998; 113:652-9.

5. Wisser W, Senbaklavaci O, Ozpeker C, Ploner M, Wanke T, Tschernko E, et al. Is long-term functional outcome after lung volume reduction surgery predictable? Eur J Cardiothorac Surg. 2000;17:66672

6. Criner GJ, Cordova FC, Furukawa S, Kuzma AM, Travaline JM, Leyenson V, et al. Prospective randomized trial comparing bilateral lung volume reduction surgery to pulmonary rehabilitation in severe chronic obstructive pulmonary disease. Am J Respir Crit Care Med. 1999;160:2018-27.

7. Pompeo E, Marino M, Nofroni I, Matteucci G, Mineo TC. Reduction pneumoplasty versus respiratory rehabilitation in severe emphysema: a randomized study. Pulmonary Emphysema Research Group. Ann Thorac Surg. 2000;70:948-53.

8. Geddes D, Davies M, Koyama H, Hansell D, Pastorino U, Pepper J, et al. Effect of lung-volume-reduction surgery in patients with severe emphysema. N Engl J Med. 2000;343:239-45.

9. Gierada DS, Yusen RD, Villanueva FS, Pilgram TK, Slone RM, Lefrak SS, et al. Patient selection for lung volume reduction surgery: an objective model based on prior clinical decisions and quantitative CT analysis. Chest. 2000;117:991-8.

10. Wisser W, Klepetko W, Kontrus M, Bankier A, Senbaklavaci O, Kaider A, et al. Morphologic grading of the emphysematous lung and its relation to improvement after lung volume reduction surgery. Ann Thorac Surg. 1998;65:793-9.

11. Weder W, Thurnheer R, Stammberger U, Burge M, Russi EW, Bloch KE. Radiologic emphysema morphology is associated with outcome after surgical lung volume reduction. Ann Thorac Surg. 1997;64:31320.

12. Thurnheer R, Engel H, Weder W, Stammberger U, Laube I, Russi EW, et al. Role of lung perfusion scintigraphy in relation to chest CT and pulmonary function in the evaluation of candidates for lung volume reduction surgery. Am J Respir Crit Care Med. 1999;159:301-10.

13. Russi EW, Stammberger U, Weder W. Lung volume reduction surgery for emphysema. Eur Respir J. 1997;10:208-18.

14. Stammberger U, Klepetko W, Stamatis G, Hamacher J, Schmid RA, Wisser W, et al. Buttressing the staple line in bilateral thoracoscopic 
lung volume reduction surgery: a randomized, three-center study. Ann Thorac Surg. 2000;70:1820-5.

15. Jaakkola MS, Jaakkola JJK. Assessment of exposure to environmental tobacco smoke. Eur Respir J. 2001;10:2384-97.

16. American Thoracic Society. Surveillance for respiratory hazards in the occupational setting. Am Rev Respir Dis. 1982;126:952-6.

17. Bland M. An introduction to medical statistics. 1st ed. Oxford: Oxford University Press; 1987.

18. Zar JH. Testing for goodness of fit. Biostatistical analysis. Englewood Cliffs (NJ): Prentice-Hall, Inc; 1974. p. 41-58.

19. Fessler HE, Permutt S. Lung volume reduction surgery and airflow limitation. Am J Respir Crit Care Med. 1998;157:715-22.

20. Wilkens H, Demertzis S, König J, Leitnaker CK, Schäfers HJ, Sybrecht GW. Lung volume reduction surgery versus conservative treatment in severe emphysema. Eur Respir J. 2000;16:1043-9.

21. Anthonisen NR, Connett JE, Kiley JP, Altose MD, Bailey WC, Buist AS, et al. Effects of smoking intervention and the use of an inhaled anticholinergic bronchodilator on the rate of decline of $\mathrm{FEV}_{1}$. The Lung Health Study. JAMA. 1994;272:1497-505.

\section{Discussion}

Dr Joel Cooper (St Louis, Mo). I congratulate Dr Weder and his colleagues on an outstanding series and terrific results in a difficult group of patients.

Dr Weder's report confirms the long-term benefit produced by LVRS and suggests that maybe the restrictive selection criteria we have adhered to in the past might be somewhat relaxed. Because LVRS is a palliative procedure and because emphysema is an unrelenting and progressive disease, much of the controversy surrounding LVRS centers on how much benefit is produced, how long it lasts, and for which patients the magnitude and the duration of benefit justifies the risk to the patient and the cost to the payer.

On the basis of short-term data, others have suggested that the rate of decline in lung function after LVRS might somehow be accelerated, but Dr Weder's thoughtful analysis demonstrates that the benefit persists for years. This is consistent with our own recent analysis of 5 years' follow-up on our first 200 patients, showing that, on average, the benefit persists for 5 years or more and that it takes at least 3 years for half of the improvement in the $\mathrm{FEV}_{1}$ to be lost.

Dr Weder's results have again confirmed that the patients with a heterogeneous pattern of destruction benefit the most from LVRS, but his analysis suggests that the loss of benefit follows a similar logarithmic decay for each of the 3 different morphologic patterns he has identified.

I have 3 questions.

The first relates to your selection process. In your manuscript you noted that you had 51 patients with a more ideal heterogeneous pattern, and 27 patients in this series had the more diffuse homogeneous pattern, and yet we see 3 or 4 patients with a homogeneous pattern for every one we see with a more favorable pattern. How do you select among those patients, and specifically, because the morphologic patterns that you have demonstrated are based on regional differences and not absolute severity, do you tend to shy away from the patients with homogeneous severe destruction?

The second and third questions relate to the results. In all patients LVRS produces improved mechanics by reducing hyperinflation, and this is reflected in a reduction in RV and an improvement in the $\mathrm{FEV}_{1}$. But in patients with heterogeneous disease, it may also improve gas exchange by redistributing ventilation, and this is reflected in the improvement in $\mathrm{Po}_{2}$ and the reduction in oxygen requirements. Did you, in your series, see less benefit in terms of gas exchange improvement in the patients with a homogeneous pattern?

Finally, your analysis and that of most of us is focused primarily on the $\mathrm{FEV}_{1}$, but I increasingly believe that the long-term benefits of volume reduction may have more to do with a reduction in the hyperinflation, as reflected in the RV, than it does with the improvement in the $\mathrm{FEV}_{1}$. Have you any thoughts on that matter or have you analyzed the follow-up in RV in a similar fashion?

Dr Weder. Thank you very much for these 3 questions. The first question concerns the selection of patients with more homogeneous disease and whether we are more selective in picking them. We select patients with no distinct target areas for resection only if all selection criteria are fulfilled. We are especially strict in excluding patients with a very low functional reserve-expressed by carbon monoxide diffusion capacity below $20 \%$ predicted or an $\mathrm{FEV}_{1}$ below $20 \%$ predicted. Additionally, the information from the visual analysis of the CT scan is included. Unfortunately, the radiologic criteria of a too destroyed and almost vanished lung are not defined with respect to lung volume reduction surgery. Therefore, some patients might also be excluded from surgery based on the clinical judgment of a radiologically too destroyed lung.

The second point concerns changes in gas exchange with regard to the morphology. You suspect that patients with markedly heterogeneous emphysema show much more improvement in terms of gas exchange. In fact, we found a trend of more improvement only in heterogeneous disease but no significant difference between the 3 morphologic groups.

The last question regards the measurement of $\mathrm{FEV}_{1}$ as the best indicator for qualifying this procedure. Again, many of us have observed patients who claimed a clear benefit from this procedure without having a great change in $\mathrm{FEV}_{1}$ and the only improved parameter being a reduction in hyperinflation. However, most groups, including us, would like to see an improvement in $\mathrm{FEV}_{1}$, since this parameter is most widely used to validate lung function. 